\title{
VULNERABILITY AND RISK ASSESSMENT IN THE CONTEXT OF MEN AND WOMEN AGRO-PASTORALISTS IN CHAD
}

\section{国, INTRODUCTION}

The first Vulnerability and Risk Assessment (VRA) for the Employment, resilience and social cohesion in the Sahel band and the Lake Chad area project, funded by the Trust Fund (TF) in Chad took place between April and June 2017. It was led by a team including TF and Oxfam project staff in Chad, the coordinator of the consortium and two advisors in resilience from the thematic teams at Oxfam Intermón and Oxfam Solidarité. The team led the different phases of the VRA, including the preparation phase (6 weeks), analysis (13-15 June) and follow-up.

The VRA methodology makes it possible to apply a resilience approach to the programme: a systemic approach using a multi-stakeholder engagement strategy and a multi-level analysis, which allows the development of social change processes and building the capacities of women and men necessary for resilience (absorption, adaptation and transformation).

The purpose of conducting the VRA was to understand the local context, and specifically to inform Local Development Plans, as part of Objective 3 of the project: 'to strengthen the governance of local development structures and the communities' social cohesion'. A resilience approach requires the principles of inclusion, representation and participation, as well as a gender justice and a rights-based approach in the context of longterm development.

\section{$\checkmark$ THE FIVE OBJECTIVES OF THE VRA METHODOLOGY}

1. To analyse, in a detailed and collective way, the risks, vulnerabilities and capacities of local actors (women and men) to respond to shocks, stresses and uncertainties by integrating past and present causal and impact links.

2. To start the process of the collective construction of a detailed and practical action plan (to be integrated into the Trust Fund Project), which could also be used in the design/adaptation of local development plans.

3. To promote learning, collaboration, and links among partners and key stakeholders in order to subsequently facilitate the coordination of activities.

4. To build the analytical capacity of participants and the collective responsibility of local actors.

5. To document the preparation, implementation and follow-up process of the VRA, in order to ensure that it could be replicated well in other areas of the EUTF, and to use it as a case study and learning exercise in the project.

\section{(C) Oxfam International April 2018}

Published by Oxfam GB for Oxfam International under ISBN 978-1-78748-229-6 in April 2018. DOI: 10.21201/2017.2296. Oxfam GB, Oxfam House, John Smith Drive, Cowley, Oxford, OX4 2JY, UK.

Oxfam is an international confederation of 20 organizations networked together in more than 90 countries, as part of a global movement for change, to build a future free from the injustice of poverty. Please contact any of the agencies for further information, or visit www.oxfam.org 


\section{$\square$ CONTEXT CHOSEN FOR THE VRA}

The area chosen for the VRA was one covered by the sub-prefectures of Chadra, Amsilap, rural Moussoro and Michémiré. It is an agro-pastoral zone in Barh- El Gazel, where most of the Oxfam interventions of the EUTF consortium project will take place.

Due to changing rainfall patterns in recent years (late onset and failing rains), smallholder farmers have difficulty planning their cropping calendars and the transhumance routes for pastoralists.

Pastoralists have to keep moving, searching for forage, and they lose weakened livestock. Some pastoralists are increasingly agro-pastoralists: becoming sedentary and keeping their herds in the south. This creates recurrent conflict over the access and management of natural resources in this area as well as over migration.

The purpose of the VRA is to inform, through the analysis of this context, the Local Development Plans to be developed under the Objective 3 of the EUTF. For this reason, several VRA are being considered in the project areas, based on their characteristics, linking them to the nine Local Development Plans.

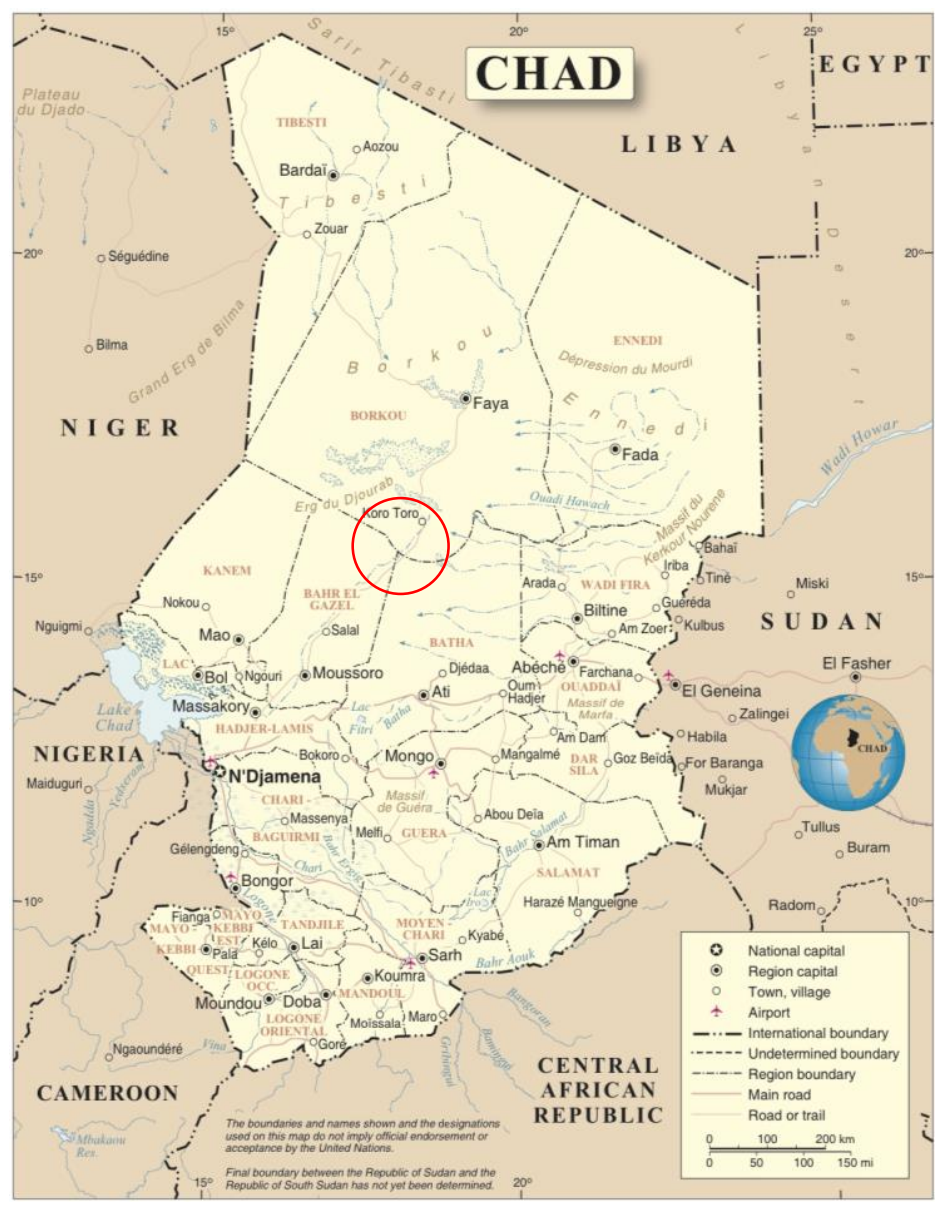

\section{$\checkmark$ METHOdOLOGY}

The VRA methodology includes a preparation phase of approximately 6 weeks before the analysis phase.

During the analysis, the following phases were established:

- The initial vulnerability assessment (IVA) allows the Knowledge Group to analyse the extent to which a social group or a livelihood activity is exposed or sensitive to relevant hazards and issues.

- The impact chain exercise (ICE) allows the Knowledge Group to assess the impacts of hazards and issues over time, by mapping their impacts throughout the system (i.e. the local area and beyond). This step also generates initial ideas about measures that can be taken to reduce the vulnerability of social groups and promote their resilience.

- The adaptive capacity analysis (ACA) allows the Knowledge Group to explore further the measures to reduce vulnerability identified in the ICE and to test their potential contribution to risk reduction and resilience over the longer term, by applying an adaptive capacity lens.

- Aligning findings with opportunities (AFO) allows the Knowledge Group (or members of the Knowledge Group in collaboration with local leaders) to consider which of the measures identified could be inserted into existing or new development plans of the community, region or other relevant level.

In the stages after the analysis, it is important to ensure that insights from the analysis are linked to the resilient governance mechanisms proposed. 


\section{THE VRA RESULTS FOR THE AGRO-PASTORAL AREA OF THE BARH-EL GAZEL}

The VRA area included the sub-prefectures of Chadra, Amsilap, rural Moussoro and Michémiré.

\section{Constitution of the Knowledge Group: Forging new links}

The VRA engaged a group of individuals for the analysis. This Knowledge Group was composed of 31 people (17 women and 14 men), and included representatives of different socioprofessional groups (breeders, market gardeners, tanners, producers, etc.), delegates from different government committees (social action, health), civil society representatives at the departmental, regional and local levels such as the CELIAF, the ADCM, the

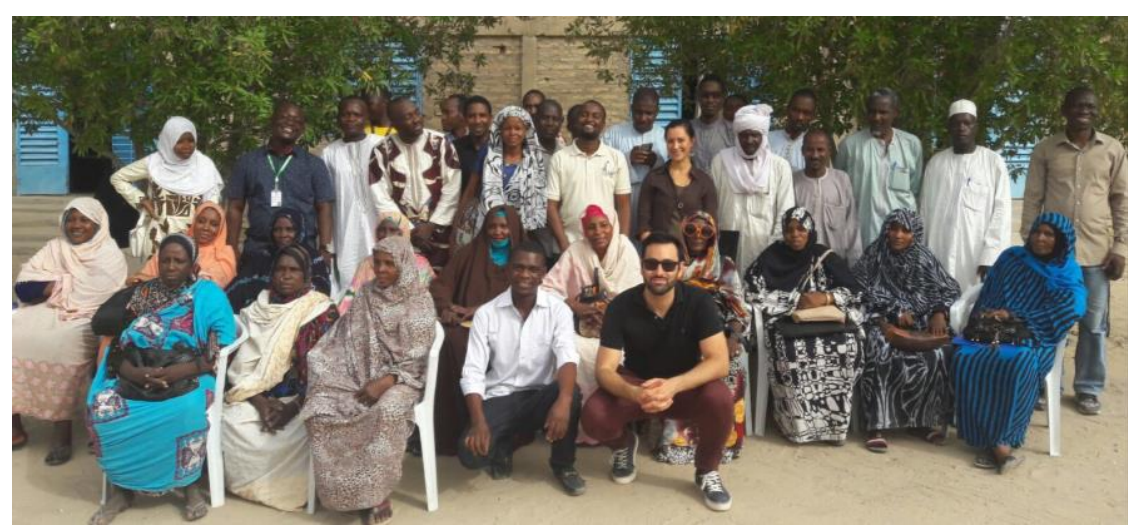
Trust Fund consortium partners (ACF, CARE, OXFAM) and its local partner AIDER, as well as a UNDP representative. It also included the Secretary General of the region, the mayor of Moussoro and the village chief of Dar-Es-Salaam in the sub-prefecture of Chaddra.

Translation into different languages and the co-facilitation tasks were ensured through two local consultants (a man and a woman), and were key to the success of the analysis; particularly considering the four languages (Gourane, Kanembou, Chadian Arabic and French) spoken among the group members and that some of them were illiterate. The group diversity and the validity of the analysis results were ensured by the exclusion of discrimination on the grounds of gender, language or social status.

\section{Collective Identification of the 11 priority risks by the Knowledge Group}

The results were obtained by a detailed and collective analysis of the risks, vulnerabilities and capacities of local actors in the face of shocks, and as result of their individual and collective engagement to take action.

An initial list of 11 priority risks was proposed after discussion, in the context of the analysis:

1. Migration of youth

2. Drought, and variations in the timing of useful rainfall

3. Low levels of schooling for young girls

4. Conflicts related to land

5. Unsupervised movements of herds

6. Parallel justice and administrative corruption

7. Early marriage of girls

8. Reluctance to include women in decision making

9. Causes of infant malnutrition (e.g. harmful practices related to nutrition)

10. Gender-based violence

11. Silting up of the 'Ouadis' (seasonal river beds).

\section{Initial analysis}

- Among the 11 priority risks, each of which have a gender dimension, four risks are caused by genderbased discrimination: low levels of schooling for girls; early marriage of girls; the reluctance to include women in decision making; and gender-based violence. 
- Risks such as the migration of young people, which is very sensitive in the framework of Trust Fund project, deserve a more detailed analysis to show the complexity of the issue and the structural causes that lead young people to migrate, and how this is related to other risks, including gender-based discrimination. For example, it is also important to understand the impact of migration from the point of view of those who cannot leave, and who have to assume responsibility for the household. This is the reality, especially for women, for whom the increase in responsibilities comes with limited privileges, limited access to resources, and discrimination.

\section{New governance dynamics initiated: inclusive and co-responsible}

\section{Results in terms of building new governance dynamics and capabilities, while promoting inclusive analysis and engagement, and representation and participation of all members of the community}

- New relations were built among the multiple stakeholders (between different professional sectors, castes, genders, geographic locations, and between state structures and community organizations, etc.), but these relationships, while potentially strong are fragile if no dynamics or process of change are engaged. The Trust Fund aims to strengthen the structures of local development (CAL, CDA, CRA), and share good governance practices to enable the development of capacities that can build resilience. Such structures will channel and implement the solutions identified for each of the risks through the Local Development Plans. However, some operational modes of these structures, as well as their current composition, are not entirely compatible with the approach initiated in the VRA analysis; for example, a lack of representation, inclusion and gender balance. Influencing work is needed for the collective and sustainable construction of governance mechanisms in order to make these structures representative, inclusive, participatory and thus able to build resilient capacities for the community. Without structures and mechanisms capable of integrating and developing good governance practices (based on representation, inclusivity, gender justice and oriented to long-term, flexible and accountable planning), the potential for developing and putting in place a local/communal development plan will be lost.

\section{RECOMMENDATIONS AND WAY FORWARD}

- A strategy for mainstreaming gender justice is essential for a resilience-oriented intervention. A simultaneous gender and power analysis is needed at all stages, including for the teams' internal ways of working, approach and communications.

- In-depth research on migration is needed to understand its causes, consequences, gender dimension, and links to resilience.

- An advocacy strategy should be developed as a priority that works with the local development structures (LDS)): CAL, CDA, CRA, as well as with other development actors, to agree on a common approach to governance that is compatible with a long-term vision, and a systemic and rights-based approach. This would entail a review of the accessibility and criteria for participation in the LDS, roles and responsibilities, and the review of the mechanisms which are currently causing dysfunctional ways of working. Such ways of working are preventing local structures from achieving Objective 3 of the Trust Fund, which sees accountable governance as one of the key processes enabling resilience.

- All partners should agree to harmonize approaches. Where partners' analysis methodologies differ slightly from the VRA, agreement on approaches for the good governance objective (Objective 3 ) is important for the consistency of the project. The principles of representation, inclusion, rights and gender should be common denominators across resilience methodologies, as is the commitment to work with multiple and diverse stakeholders at different levels. An established and common advocacy strategy should strengthen this consistency and reinforce the objectives by connecting the fieldwork outcomes with wider activity, including at district, national and/or regional levels. 